\title{
Treatment of multiple myeloma patients with autologous stem cell transplantation a fresh analysis
}

\author{
Malgorzata Wach, Maria Cioch, Marek Hus, Dariusz Jawniak, Wojciech Legiec, \\ Magdalena Malek, Joanna Manko, Adam Walter-Croneck, \\ Ewa Wasik-Szczepanek, Anna Dmoszynska
}

Department of Hematooncology and Bone Marrow Transplantation, Medical University of Lublin, Poland

\begin{abstract}
Patients with multiple myeloma (MM) treated with conventional chemotherapy have an average survival of approximately three years. High dose chemotherapy followed by autologous stem cell transplantation (ASCT), first introduced in the mid-1980s, is now considered the standard therapy for almost all patients with multiple myeloma, because it prolongs overall survival and disease free survival. Between November 1997 and October 2006, 122 patients with MM (58 females, 64 males, median age 51.0 years [ \pm 7.98] range: 30-66 years) were transplanted in the Department of Hematooncology and Bone Marrow Transplantation at the Medical University of Lublin: 47 patients were in complete remission or in unconfirmed complete remission, 66 patients were in partial remission, and nine had stable disease. Of these, there were 95 patients with IgG myeloma, 16 with IgA myeloma, one with $\operatorname{IgG} / \operatorname{IgA}$, one with $\operatorname{IgM}$ myeloma, five with non secretory type, two with solitary tumor and two with LCD myeloma. According to Durie-Salmon, 62 patients had stage III of the disease, 46 had stage II and four had stage I. Most patients (69/122) were transplanted after two or more cycles of chemotherapy, 48 patients were transplanted after one cycle of chemotherapy, one patient after surgery and rtg-therapy and four patients had not been treated. In mobilisation procedure, the patients received a single infusion of cyclophosphamide $\left(4-6 \mathrm{~g} / \mathrm{m}^{2}\right)$ or etoposide $1.6 \mathrm{~g} / \mathrm{m}^{2}$ followed by daily administration of G-CSF until the peripheral stem cells harvest. The number of median harvest sessions was $2.0( \pm 0.89)$ (range: $1-5)$. An average of $7.09( \pm 33.28) \times 10^{6} \mathrm{CD} 34^{+}$cells $/ \mathrm{kg}$ were collected from each patient (range: $\left.1.8-111.0 \times 10^{6} / \mathrm{kg}\right)$. Conditioning regimen consisted of high dose melphalan $60-210 \mathrm{mg} / \mathrm{m}^{2}$ without TBI. An average of $3.04( \pm 11.59) \times 10^{6}$ $\mathrm{CD} 34^{+}$cells $/ \mathrm{kg}$ were transplanted to each patient. Fatal complications occured in four patients (treatment-related mortality $=3.2 \%$ ). In all patients there was regeneration of hematopoiesis. The median number of days for recovery to ANC $>0.5 \times 10^{9} / 1$ was 13 ( \pm 4.69 ) (range: $10-38$ ) and platelets recovery to $>50 \times 10^{9} / 1$ was 25 days ( \pm 11.65 ) (range: $12-45$ ). Median time of hospitalization was 22 days ( \pm 7.14$)$ (range: $14-50)$. Patients were evaluated on day 100 after transplantation: $74.9 \%$ achieved CR and nCR, $14.3 \%$ were in PR, 5.4\% had SD and $5.4 \%$ had progressed. Median of OS was 45 months ( \pm 30.67$)$. OS at 3-years was $84 \%$ and at 7-years $59 \%$. Median PFS was 25 months ( \pm 26.13 ). PFS at 3 -years was $68 \%$, and at 7-years was $43 \%$. At present (November 2009) 52 patients (42\%) are still alive. High-dose chemotherapy followed by autologous stem cell transplantation is a valuable, well tolerated method of treatment for patients with MM that allows the achievement of long-lasting survival. (Folia Histochemica et Cytobiologica 2011; Vol. 49, No. 2, pp. 248-254)
\end{abstract}

Key words: multiple myeloma, high dose chemotherapy, autologous peripheral blood stem cell transplantation

Correspondence address: A. Dmoszynska, Department of Hematooncology and Bone Marrow Transplantation, Medical University of Lublin, Staszica Str. 11, 20-081 Lublin, Poland; tel.: (81) 53454 68, e-mail: annadmosz@wp.pl

\section{Introduction}

Patients with multiple myeloma (MM) treated with conventional chemotherapy have an average survival of approximately three years. After induction thera- 
py with 'old' drugs complete remission (CR) was achieved only in $3-13 \%$ of MM patients [1]. Because of the obvious resistance to conventional chemotherapy in MM, high-dose chemotherapy with autologous stem cell transplantation (ASCT) has become during the last decade the gold standard for patients aged below 65. A randomized trial by the Intergroupe Francais du Myelome (IFM) first showed a better outcome with high-dose therapy than with standard chemotherapy in 200 patients with newly diagnosed disease, with a response rate (RR) increased to $50 \%$ and overall survival $(\mathrm{OS})>5$ years [2]. Novel agents such as thalidomide (Talizer), bortezomib (Velcade) and lenalidomide (Revlimid) have been introduced to improve results of initial therapy before ASCT or as rescue regimens for refractory/relapsed disease. Using these drugs in combination with cyclophosphamide, dexamethasone and antracyclins has achieved RR up to $95 \%$ and CR rate up to $44 \%$ before ASCT $[3,4]$.

The results of myeloablative allogeneic transplantation still remain disappointing due to high transplantation-related mortality. Therefore it not recommended as a routine procedure even for younger patients with MM.

\section{Material and methods}

Patients and disease characteristics. Between November 1997 and December 2006, 122 patients with MM were transplanted in the Department of Hematooncology and Bone Marrow Transplantation in the Medical University of Lublin. Clinical charactersictics of the patients are presented in Table 1.

ASCT procedure. Peripheral blood stem cells (PBSC) collection. After induction therapy, all patients received a single infusion of cyclophosphamide $\left(4-6 \mathrm{~g} / \mathrm{m}^{2}\right)$ or an infusion of etoposide $\left(1.6 \mathrm{~g} / \mathrm{m}^{2}\right.$ divided into two doses) followed by daily i.v. administration of G-CSF at a dose of $10 \mathrm{ug} / \mathrm{kg}$ from day +5 or from +3 for the etoposide regimen until the peripheral stem cell harvest. Peripheral blood stem cells (PBSC) were collected during an average of two aphereses ( \pm 0.89$)$, (range: $1-5)$ on Haemonetics or a Baxter cell separator. The median number of collected $\mathrm{CD} 34^{+}$cells was $7.09 \times 10^{6} / \mathrm{kg}( \pm 33.28)\left(\right.$ range: $\left.1.8-111.0 \times 10^{6}\right)$ per patient. Transplant material was stored at $10 \%$ DMSO and autologous plasma or $5 \%$ albumins in $-180^{\circ} \mathrm{C}$, without rate controlled freezing.

Transplantation procedure. High-dose therapy consisted of melphalan (MEL) given i.v. at a dose of $200 \mathrm{mg} / \mathrm{m}^{2}$ or $140 \mathrm{mg} / \mathrm{m}^{2}$, followed by infusion of a median $3.04 \times 10^{6} / \mathrm{kg}$
Table 1. Clinical characteristics of transplanted patients

\begin{tabular}{|l|c|}
\hline Total number of transplanted patients & 122 \\
\hline Number of patients with double transplantation & 25 \\
\hline Age (years, median) & $51.0( \pm 7.98)$ \\
& (range: $30-66)$ \\
\hline Female/male (number) & $59 / 63$ \\
\hline Disease characteristics (number of patients) & \\
IgG MM & 94 \\
IgA MM & 17 \\
IgG/IgA MM & 1 \\
IgM MM & 1 \\
Light chain disease & 2 \\
Non secretory MM & 5 \\
Plasmacytoma & 2 \\
Kappa chain MM & 98 \\
Lambda chain MM & 21 \\
No data & 3 \\
Stage I (acc. Durie-Salmon) & 4 \\
Stage II (acc. Durie-Salmon) & 46 \\
Stage III (acc. Durie-Salmon) & 62 \\
No data & 8 \\
\hline Therapy before transplantation & \\
(number of patients) & \\
One cycle of chemotherapy & \\
(VAD or VMBCP or THAL)* & \\
Two or more cycles of chemotherapy & \\
(VAD, EDAP, CTD, VD,THAL, MP)* & \\
Surgery and rtg therapy & \\
Any treatment & 4 \\
\hline Status before transplantation (number of patients) & \\
nCR & \\
CR & \\
PR & \\
SD & \\
Not treated & \\
\hline
\end{tabular}

* VAD - vincristine, adriblastine, dexamethasone;

VMBCP - vincristine, melphalan, carmustine, cyclophosphamide, prednisone; THAL — thalidomide; EDAP — etoposide, dexamethasone, arabinoside cytosine, cisplatine; CTD — cyclophosphamide, thalidomide, dexamethasone, MP — melphalan, prednisone; VD — vinorelbine, dexamethasone

$( \pm 11.59)$, (range: $1.15-5.0 \times 10^{6} / \mathrm{kg}$ ) non selected CD34+ cells on day 0 . TBI was not used. G-CSF was administered subsequently i.v. at a dose of 5-10 ug $/ \mathrm{kg}$.

In 25 patients, tandem transplants were performed. They received MEL $200 \mathrm{mg} / \mathrm{m}^{2}$ or $140 \mathrm{mg} / \mathrm{m}^{2}$ and one of them received Busulfan $4 \mathrm{mg} / \mathrm{kg}$ followed by reinfusion of stem cells.

\section{Results}

Patients were evaluated on day 100 after transplantation. $74.9 \%$ achieved CR and $\mathrm{nCR}, 14.3 \%$ were in PR, 5.4\% of them had SD and 5.4\% progressed.

Median OS was 45 months ( \pm 30.67) for patients with one transplantation, and 83 months $( \pm 32.35)$ for doubly transplanted patients, $p=0.1089$. Progression free survival (PFS) was median 25 months 
Table 2. Clinical data during transplantation

\begin{tabular}{|c|c|}
\hline Duration of neutropenia (median, days) & $\begin{array}{c}13 \\
\text { (range: } 10-38 \text { ) }\end{array}$ \\
\hline Duration of thrombocytopenia (median, days) & $\begin{array}{c}25 \\
\text { (range: } 12-45 \text { ) }\end{array}$ \\
\hline Days of hospitalization (median) & $\begin{array}{c}22 \\
\text { (range: } 14-50 \text { ) }\end{array}$ \\
\hline Days of G-SCF administration (median) & $\begin{array}{c}14 \\
\text { (range: } 0-33 \text { ) }\end{array}$ \\
\hline $\begin{array}{l}\text { Transplant-related toxicity } \\
\text { Transplant-related mortality } \\
\text { (number of patients, \%) } \\
\text { Mucositis grade gr. } 3 / 4 \text { WHO } \\
\text { (number of patients) } \\
\text { Sepsis (number of patients) } \\
\text { Pneumonia (number of patients) } \\
\text { Infections of CVC (number of patients) } \\
\text { Cardiac toxicity (MAS, FA) } \\
\text { (number of patients) }\end{array}$ & $\begin{array}{c}4(3.2 \%) \\
24 / 122 \\
\\
2 / 122 \\
1 / 122 \\
20 / 122 \\
2 / 122\end{array}$ \\
\hline
\end{tabular}

$( \pm 26.13)$ in the first group and 45 months $( \pm 30.73)$ in the second group, $\mathrm{p}=0.1043$.

In all patients, OS at 3-years was $84 \%$, PFS was $68 \%$; at 7 -years, OS was $59 \%$ and PFS was $43 \%$ (Figures 1-3). At present (November 2009) 52 patients $(42 \%)$ are still alive.

The clinical course of transplantation is summarized in Table 2, and the results of ASCT are shown in Table 3.

\section{Discussion}

MM is characterized by a marked resistance to conventional chemotherapy. It has been shown that drug resistance can be overcome by dose escalation [5-7]. High-dose therapy with MEL was introduced in the mid-1980s [8]. The IFM randomized trial first demonstrated the superiority of high-dose therapy supported by autologous bone marrow transplantation compared to conventional chemotherapy, with OS at 7 -years of $43 \%$ vs. $27 \%(\mathrm{p}<0.03)$ and EFS at 7-years of $16 \%$ vs. $8 \%$ (p < 0.01 ) [2]. Five more trials were performed to compare ASCT versus conventional chemotherapy, and whereas three of them showed no benefit in terms of EFS or OS [9-11], the other two confirmed the benefit, with median OS of 54 months and OS at 3-years of $77 \%[12,13]$.

Many factors can be responsible for ASCT outcome, including biological and individual factors before transplantation, genetic factors, biological parameters, $\beta 2$-microglobulin and albumin levels forming International Staging System, sensitivity to initial chemotherapy, and proliferative index $[14,15]$. CR status before ASCT has been revealed to be the
Table 3. Comparison of clinical status before and after ASCT

\begin{tabular}{|l|c|c|}
\hline & $\begin{array}{c}\text { Status before } \\
\text { transplantation (\%) }\end{array}$ & $\begin{array}{c}\text { Status at day +100 } \\
\text { after ASCT (\%) }\end{array}$ \\
\hline $\mathrm{nCR}$ & 3.3 & 2.7 \\
\hline $\mathrm{CR}$ & 35.8 & 72.2 \\
\hline $\mathrm{PR}$ & 53.6 & 14.3 \\
\hline $\mathrm{SD}$ & 7.3 & 5.4 \\
\hline Relapse & & 5.4 \\
\hline
\end{tabular}

most important factor contributing to a long-lasting response and prolonged survival in patients with MM $[16,17]$. Sensitivity to initial chemotherapy measured by the M-protein type at time of transplant is the most reliable predictor of CR after ASCT [16, 17]. A recent meta-analysis carried out by Van de Velde et al. also confirmed the strong association between maximal response to induction therapy and longterm outcome after ASCT [18]. The chromosomal abnormalities del $(13), t(4,14)$ and $\operatorname{del}(17 p)$ have been associated with a shorter survival after ASCT and have become a marked risk factor for all MM patients [19].

Novel agents (i.e. thalidomide, lenalidomide and bortezomib) have been introduced. They have an increased anti-myeloma effect and prolong survival due to better results of initial therapy before ASCT and/ /or more effective rescue regimens for patients with relapsed/refractory disease.

Thalidomide-based regimens as initial therapy in multiple myeloma: TD (thalidomide + dexamethasone); TAD (thalidomide + dexamethasone + adriamycin); and CTD (cyclo-phosphamide + thalidomide + dexamethasone) have resulted in raising the response rate (RR) $-72 \%$ to $87 \%$ and CR rate up to $19 \%$ before ASCT. After transplantation, RR rate increased to $88 \%$, including $\mathrm{CR}$ and $\mathrm{nCR}$ rates up to $51 \%[20,21]$.

Lenalidomide-based therapy was applied in MM patients in two trials conducted by ECOG and SWOG with RR $82 \%$ and $85 \%$ respectively and CR rate $4 \%$ and $22 \%$ before transplantation, with OS at 4-years 92\% after ASCT [22].

Bortezomib in combination with thalidomide or lenalidomide or anthracyclins or dexamethasone boosted RR from $60 \%$ to $95 \%$, with $10 \%$ to $44 \%$ CRs. In all these pilot studies, the CR markedly increased after transplantation (31-57\%) [3, 4].

During the nine years of this study, 122 patients with multiple myeloma were transplanted in the Department of Hematooncology and Bone Marrow Transplantation in Lublin. Different regimens before ASCT were applied: VAD, EDAP, VMBCP, CTD, 


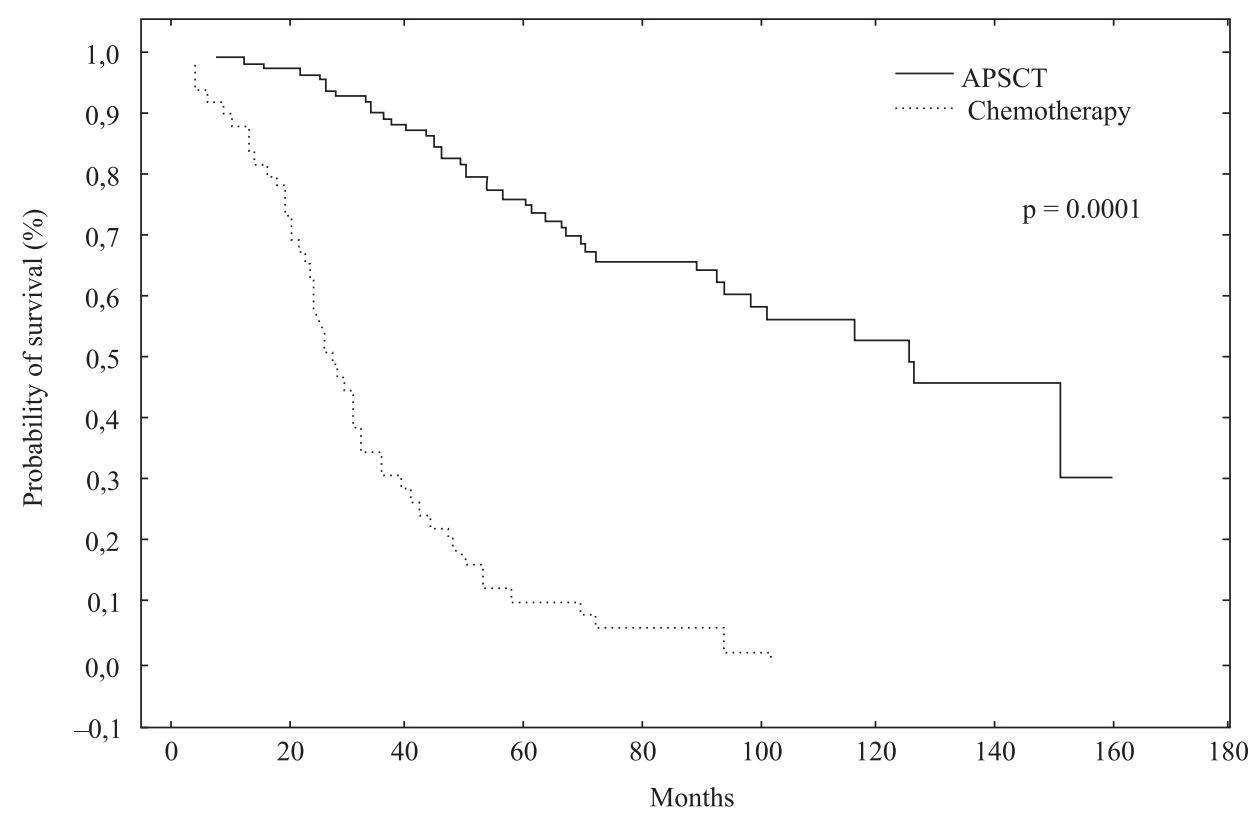

\begin{tabular}{|l|c|c|c|}
\hline & Median & Mean & SD \\
\hline APSCT & 66.41 & 74.83 & 36.49 \\
\hline Chemotherapy & 27.00 & 33.14 & 22.89 \\
\hline
\end{tabular}

Figure 1. Overall survival of transplanted patients in contrast to conventional chemotherapy in Department of Hematooncology and Bone Marrow in Lublin data (months)

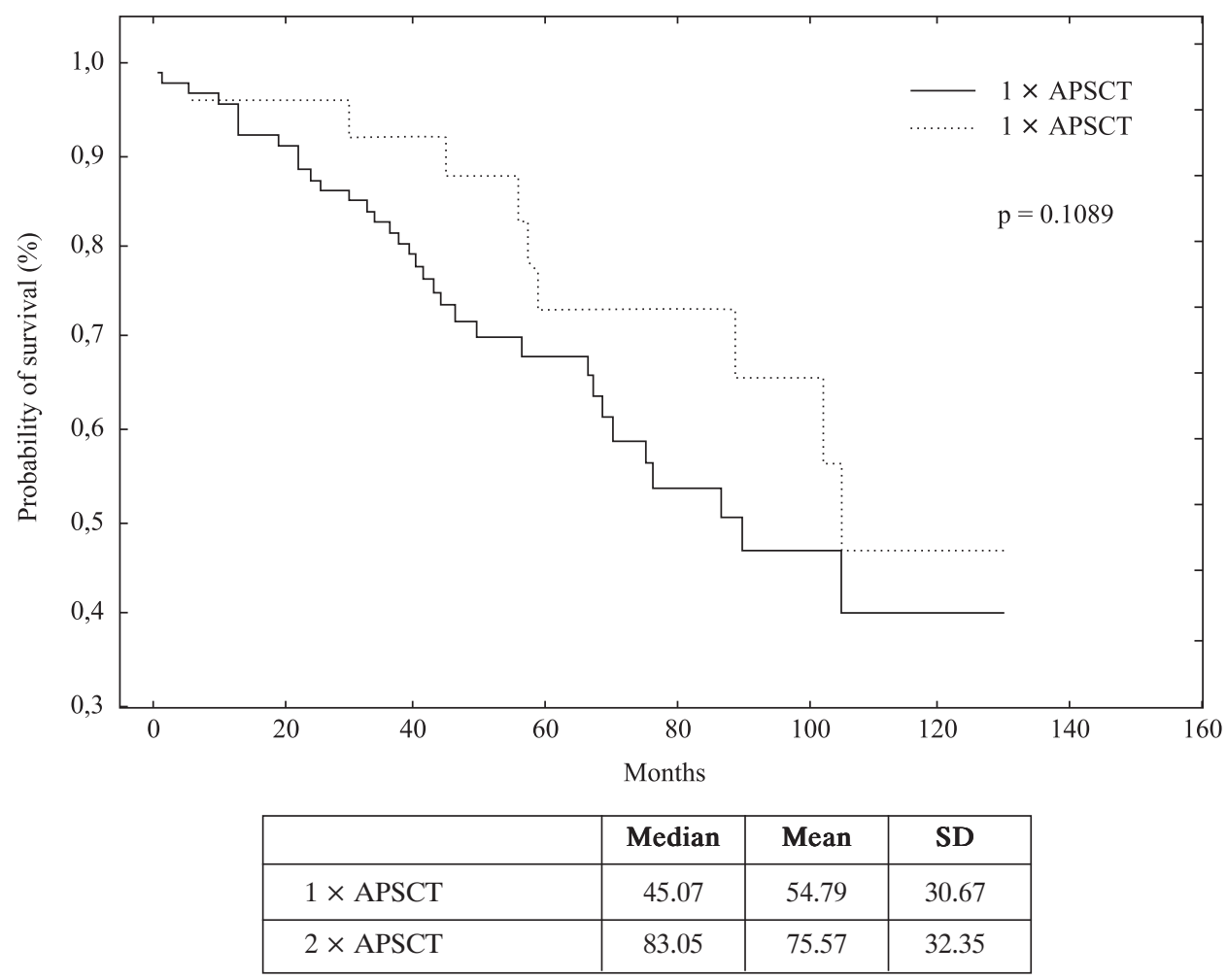

Figure 2. Overall survival of transplanted patients (months) $-122 \mathrm{pts}$ 


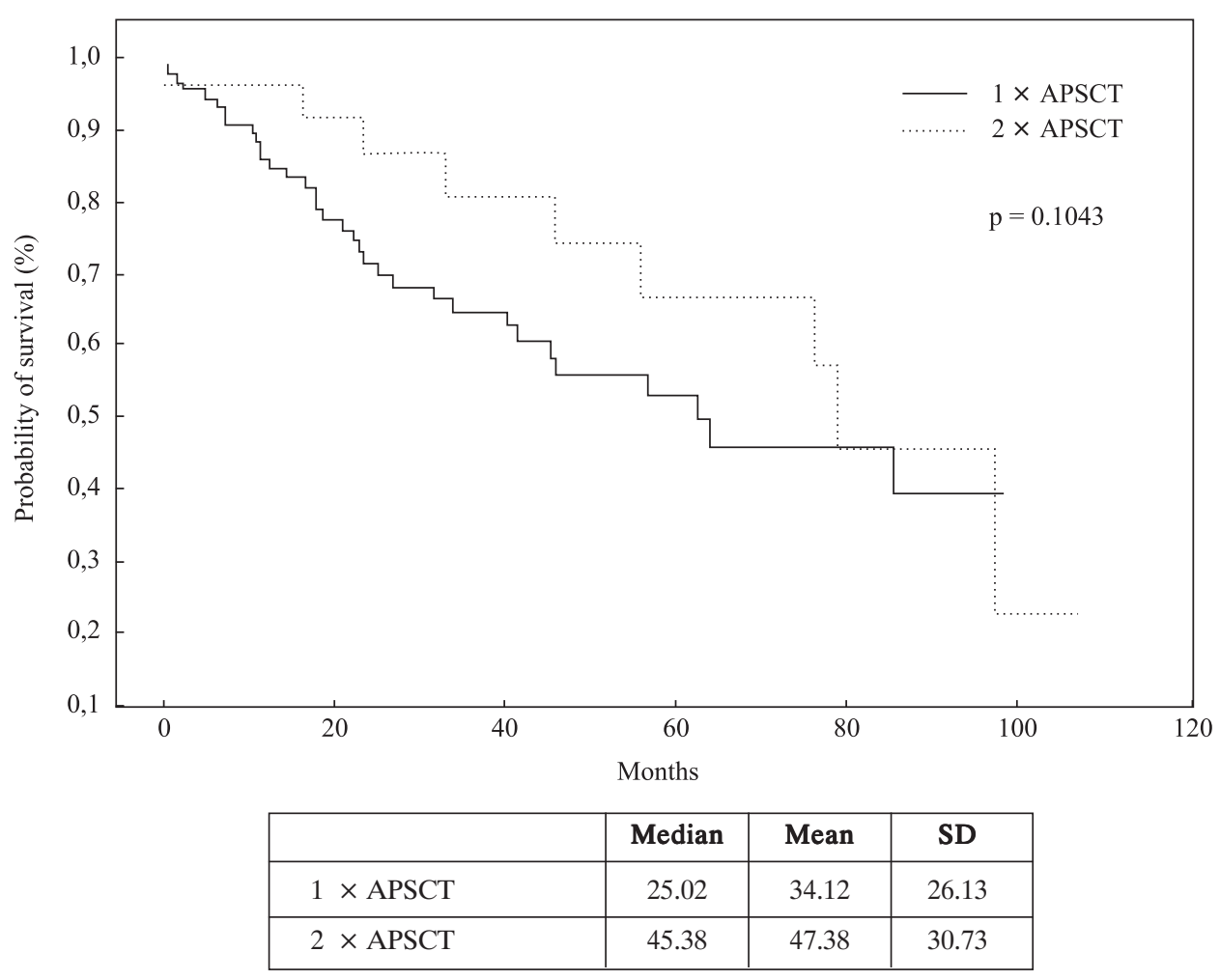

Figure 3. Progression free survival after transplantation (months) -122 pts

thalidomide alone, and vinorelbine with dexamethasone. We tried to obtain the best response before transplantation. Only a few patients received one cycle; most received two or more cycles of therapy. RR was high: $92.7 \%$ with $\mathrm{CR}$ and $\mathrm{nCR}$ rate was $39.1 \%$. After ASCT, $74.9 \%$ of patients obtained CR and nCR, $14.3 \%$ PR, $5.4 \%$ of them had SD and $5.4 \%$ had progressed. Median of OS was 45 months, OS at 3-years was $85 \%$ and at 7 -years was $59 \%$. TRM was low at $3.2 \%$. Published data referring to TRM at that time gave figures ranging from $2.7 \%$ to $10 \%[23,24]$.

Autologous stem cell transplantation does not cure the condition. Most patients will relapse within a median of three years. It has been suggested that double transplantation could be more effective than single transplantation to cure patients with multiple myeloma or to prevent relapse. The IFM 94 study compared single versus double ASCT among 399 patients and showed no benefit of double ASCT: at 7-years OS was $21 \%$ and EFS $20 \%$. This trial confirmed the benefit of double ASCT only in patients who failed to achieve a very good partial response after the first transplantation [25]. Four further trials comparing single versus double transplantation were conducted, and two of them reported a survival benefit in favour of tandem transplantation [10, 26-28].
In 25 patients, tandem transplantation was performed in our centre. OS was median 83 months $( \pm 32.35)$, mean 75.57 months and PFS was 45 months ( \pm 30.73), mean 47.38 months. They reached OS at 7 -years $73 \%$, compared to OS $59 \%$ in once transplanted patients and EFS $67 \%$ vs. $43 \%$ respectively. But in longer observation (ten years) there were no significant differences observed in OS and EFS when comparing single versus double transplantation.

Maintenance therapy after ASCT has been applied for many years in MM patients. First, interferon alpha prolonged PFS and OS by between 4 and 8 months [29]. The IFM group and the Australian group showed that maintenance therapy with thalidomide prolonged duration of PFS and OS after ASCT $[30,31]$. In the IFM trial, OS at 4-years was $87 \%$ and PFS at 3-years was $52 \%$. In the Australian group, OS at 3 -years was $86 \%$ and PFS at 3 -years was $42 \%$. Today, thalidomide is recommended as a maintenance therapy for less than 12 months and for patients who do not achieve CR after ASCT. Lenalidomide is now considered as the ideal maintenance drug, but clinical trials are still ongoing. We used routine maintenance therapy with thalidomide at a dose of $100 \mathrm{mg}$ daily or interferon alpha at a dose of $3 \mathrm{mln} \mathrm{U} /$ three times weekly in cases where CR or nCR after ASCT was not obtained. These therapies were applied until progression and were well tolerated. 
ASCT is currently considered to be the standard therapy for younger patients with MM, safe due to a low mortality rate (1-2\%), with benefits in terms of response rate, particulary in EFS with ranges between 25 and 42 months compared to conventional chemotherapy. Patients after ASCT have a very good quality of life, with some of them requiring only maintenance therapy instead of sequential chemotherapy.

\section{Acknowledgements}

Andrzej Brzozowski, Tomasz Gromek, Monika Legiec, Magdalena Kosicka.

\section{References}

1. Alexanian R, Dimopoulos M. The treatment of multiple myeloma. N Engl J Med. 1994; 7:484.

2. Attal M, Harousseau J, Stoppa A et al. A prospective randomized trial of autologous bone marrow transplantation and chemotherapy in multiple myeloma. $N$ Eng $J$ Med. 1996;335:1844-1845.

3. Oakervee HE, Popat R, Curry N et al. PAD combination therapy (PS-341/bortezomib, doxorubicin, dexamethasone) for previously untreated patients with multiple myeloma. Br J Hametol. 2005;129:755-762.

4. Richardson P, Sagar L, Jakubowiak A et al. Lenalidomide, bortezomib and dexamethasone in a patient with newly diagnosed multiple myeloma: encouraging efficacy in high risk groups with updated results of phase I/II study. Blood. 2008;112:93a.

5. Barlogie B, Jagannath S, Desikan KR et al. Total therapy with tandem transplants for newly diagnosed multiple myeloma. Blood. 1999;93:55-65.

6. Mc Elwain T, Powles R. High-dose intravenous melphalan for plasma-cell leukemia and myeloma. Lancet. 1983;2:822.

7. Selby PJ, Mc Elwain TJ, Nandi AC et al. Multiple myeloma treated with high dose intravenous melphalan. $\mathrm{Br} J \mathrm{Hae}-$ matol. 1987;66:55.

8. Barlogie B, Hall R, Zander A, Dicke K, Alexanian R. High dose melphalan with autologous bone marrow transplantation for multiple myeloma. Blood. 1986;67:1298.

9. Barlogie B, Kyle RA, Anderson KC et al. Standard chemotherapy compared with high-dose chemoradiotherapy for multiple myeloma; final results of the chase III US Intergroup trial S4321. J Clin Oncol. 2006;24:929-936.

10. Fermand JP, Katsahian S, Divine M et al. High-dose therapy and autologous blood stem-cell transplantation compared with conventional treatment in myeloma patients aged 55 to 65 years: long-term results of a randomized control trial from the Group Myelome-Autogreffe. J Clin Oncol. 2005;23:9227.

11. Blade J, Rosinol L, Sureda A et al. High-dose therapy intensification compared with continued standard chemotehrapy in multiple myeloma patients responding to the initial chemotherapy: long-term results from a prospective randomized trial from the Spanish cooperative group PETHEMA. Blood. 2005;106:3755-3759.

12. Child JA, Morgan GJ, Davies FC et al. High-dose chemotherapy with hematopoietic stem-cell rescue for multiple myeloma. N Engl J Med. 2003;348:1875-1883.
13. Palumbo A,Bringhen S, Petrucci MT et al. Intermediatedose melphalan improves survival of myeloma patients aged 50 to 70: results of a randomized controlled trial. Blood. 2004;104:3052-3057.

14. Attal M, Moreau P, Avet-Loiseau H, Harousseau J-L. Stem cell transplantation in multiple myeloma. Hematol. 2007;311-316.

15. Greippp PR, San Miguel JS, Durie BG et al. International staging system for multiple myeloma. J Clin Oncol. 2005;23:3412-3420.

16. Alexanian $\mathrm{R}$, Weber $\mathrm{D}$, Giralt $\mathrm{S}$ et al. Impact of complete remission with intensive therapy in patients with responsive multiple myeloma. Bone Marrow Transplant. 2001;27:1037-1044 .

17. Nadal E, Gine E, Blade J et al. High-dose therapy/autologous stem cell transplantation in patients with chemosensitive multiple myeloma: predictors of complete remission. Bone Marrow Transplant. 2004;33:61-64.

18. Van de Velde HJK, Liu X, Chen G, Cakana A, Deraedt W, Bayssas M. Complete response correlates with long-term survival and progression-free survival in high-dose therapy in multiple myeloma. Haematologica. 2007;92:1399-1406.

19. Avet-Loiseau H, Attal M, Moreau P et al. Genetic abnormalities and survival in multiple myeloma: the experience of the Intergroupe Francophone du Myelome. Blood. 2007;109:3412-3495.

20. Lokhors HM, Schmidt-Wolf I, Sonneveld P et al. Thalidomide in induction treatment increases the very good partial response rate before and after high-dose therapy in previously untreated multiple myeloma. Haematologica. 2008;93:124-127.

21. Morgan GJ, Faith D, Roger O et al. Thalidomide combination improves response rates; results from the MRC IX study [abstract]. Blood. 2007;110:3593.

22. Rajkumar SV, Jacobus S, Callander N et al. Randomized trial of lenalidomide plus high-dose dexamethasone versus lenalidomide plus low-dose dexamethasone in newly diagnosed myeloma (EaA03), a trial coordinated by the Eastern Cooperative Oncology Group: analysis of response, survival, and outcome [abstract]. J Clin Oncol. 2008;26:8504.

23. Fermand JP, Ravaud P, Chevret S et al. High-dose therapy and autologous peripheral blood stem-cell transplantation in multiple myeloma: up-front or rescue treatment? Results of a multicenter sequential randomized trial. Blood. 1998;92:3131.

24. Lenhoff S, Hjorth M, Holmberg E et al. Impact on survival of high-dose therapy with autologous stem cell support in patients younger than 60 years with newly diagnosed multiple myeloma: a population-based study. Blood. 2000;95:7-11.

25. Attal M, Harrousseau JL, Facon T et al. Single versus double autologous stem cell transplantation for myeloma. N Engl J Med. 2003;349:2495-2502.

26. Cavo M, Zamagni E, Cellini $C$ et al. Single versus tandem autologous transplants in multiple myeloma: Italian experience. J Clin Oncol. 2007;25:2434-2441.

27. Goldschmidt H. Single versus double high-dose therapy in multiple myeloma: second analysis of the trial GMMG-HD2 [abstract]. Hematol J. 2005;90:38. 
28. Sonneveld P, Van Der Holt B, Sergeren CM et al. Intensive versus double intensive therapy in untreated multiple myeloma. Updated analysis of the prospective phase III study Hovon 24-MM [abstract]. Hematol J. 2005;90: 37-38.

29. San-Miguel JF and Mateos MV. How to treat a newly diagnosed young patient with multiple myeloma. Hematol. $2009 ; 555-565$.
30. Attal M, Harousseau JL, Leyvraz S et al. Maintenance therapy with thalidomide improves survival in patients with multiple myeloma. Blood. 2006;108:3289-3294.

31. Spencer A, Prince HM, Roberts AW et al. Consolidation therapy with lo-dose thalidomide and prednisolone prolongs the survival of multiple myeloma patients undergoing a single autologous stem-cell transplantation procedure. J Clin Oncol. 2009;27:1788-1793.

Submitted: 29 June, 2010

Accepted after reviews: 30 November, 2010 